\title{
Autism Spectrum Disorder Combined with Mental Retardation- An Indication for Molecular-Genetic Examination?
}

\author{
Andreas Frei* $^{*}$ \\ Forensischer Psychiater Psychotherapeut FMH, Inseliquai 10, 6005 Luzern, Switzerland \\ *Corresponding Author: Dr. Andreas Frei, Forensischer Psychiater Psychotherapeut FMH, Inseliquai 10, 6005 \\ Luzern, Switzerland, Tel: 0041412100137; E-mail: andreas54frei@hin.ch
}

Received: 16 May 2018; Accepted: 22 May 2018; Published: 28 May 2018

\section{Background}

Patients suffering from mental retardation have a smaller risk of becoming criminals than other people. This is, however, not true for violent crimes: The risk to be prosecuted for violent crime is said to be twice for men, for women it is even twelve times higher than for the average population. This risk is especially high when there is a comorbid psychiatric disorder as e.g. an autism spectrum disorder [1]. Contrary to the average population, the prevalence of aggression is equal for both sexes. Autistic children who are violent have a poor prognosis [2].

This report discusses the case of a young woman suffering from mental retardation and a comorbid autism spectrum disorder who committed a serious violent crime. Since the causes of mental retardation are usually genetically founded [3], I will - after having described the case report and the related diagnostic deliberations - ask questions about the limitations of the usual categorical-descriptive diagnosis, as is usual in current forensic-psychiatric practice.

Keywords: Mental retardation; Comorbid psychiatric disorder; Autistic children; Comorbid autism spectrum disorder; Forensic-psychiatric practice

\section{Case Report}

Veronika was born in 1996 as the second of five to a mother with children from three different men. Her elder brother is suffering from cerebral palsy, a younger half-brother from dyscalculia. She has no contact to her father who is said to be short-tempered; a brother of her mother is probably suffering from adult ADHD. Veronika considers the long-term spouse of her mother and father of her half-brother, who also suffers from a psychiatric 
disorder not otherwise specified, as her real father. When Veronika was five months old, her mother noticed problems with the development of her motor skills; she was not able to speak before the age of four. After the birth of her half-brother, Veronika had to be referred to a foster home, since her mother was overstrained with the education of Veronika who was very jealous of her younger brother. In 2003, at the age of seven, Veronika was described as a developmentally retarded child with deficiencies of speech and concentration and an impaired frustration tolerance. She showed marked abnormalities of conduct such as hitting the head against a wall, excessive masturbation and regressive behaviour. For some time, there was the suspicion of sexual abuse which remained, however, not substantiated. The diagnosis of "autism" was explicitly rejected, instead the diagnoses of "reactive attachment disorder of childhood" or "combined developmental disorder" and "minor mental retardation" were discussed.

In the same year, Veronika was given an educational guardian. Since her sixth year, Veronika been treated with psychopharmacological drugs such as e.g. Laevopromazin. Several children in her foster home had to consult a doctor for fear of Veronika. At the age of nine, Veronika was referred to a paediatric university clinic for further examination. The level of her cognitive development was said to correspond to that of a five years and four months old child, her capacities of speech to that of a three year old. There were no signs of cerebral palsy. The diagnoses were "severe developmental retardation especially of speech", "conduct disorder with aggressive behavioural and motor clumsiness". Veronika was then treated with Risperidone.

From August 2007 to September 2013, Veronika was placed in a rural home for special pedagogics. It was reported that her high potential for violent behaviour against people and furniture, her autoaggressive acts, her jealousy, her lacking tolerance of frustration, her verbal injuries and her sadistic traits required a one to one monitoring. Her outbursts were so violent that she had to be isolated, for her own protection as well as that of others. It was noticed, however, that she had comparatively good manipulative skills. Over time, she displayed the tendency to catch and kill tiny animals such as insects or sticklebacks. In 2008, there was another extensive psychological assessment by the nearby child psychological services. The resulting diagnoses were: "Attachment disorder of childhood with disinhibition", "organic mixed affective disorder", "combined developmental disorder" and "mild mental retardation" (IQ 67). In the same year, a neuropediatric assessment was conducted: According to this Veronika would not show any dysmorphic stigmata and there were no indications for a ,syndrome“ or a neurological disorder: No pathological signs were found through an MRI of the skull, an EEG or an examination of the chromosomes. In February 2012, Veronika had to be hospitalized in a psychiatric clinic for the first time. There were considerations about a bipolar affective disorder and Veronika was treated with Haloperidol and Lithium. In September 2012, Veronika was placed in a residential home for grown-ups. From there, she had to be hospitalized in the local psychiatric clinic as an emergency three times within a very short period. The diagnoses were: "Minor mental retardation with significant impairment of behaviour requiring attention or treatment" and "combined developmental disorder".

At the end of March 2014, Veronika had to be placed in the regional psychiatric clinic. At admission, she presented herself as a young woman of $160 \mathrm{~cm}$ height and $80 \mathrm{~kg}$ weight, with carefully varnished finger and foot nails. She was described as unruly; the staff found that ritualized processes and clear rules would support her. When frustrated 
Veronika would react in a defiant way, disobey and even wet herself; she would destroy her own and third party properties, beat herself and throw her head against the floor and so forth. Her fine and gross motor skills were found to be normal; Veronika was able to ride a bike, to swim and to dive. She started to discover her sexuality and showed a disinhibited behaviour towards men. Her conduct corresponded to that of a three to six year old child. It was not possible to perform a proper psychiatric examination. Veronika was treated with three different neuroleptics: Quetiapine, Risperidone and Chlorprothixen and the mood stabilizer Valproate.

\section{Offence}

During her stay in the clinic in April 2014, 14 aggressive incidents were registered, with Veronika attacking fellow patients or damaging property. Most embarrassing was her habit of snatching the glasses from nurses' faces and destroying them. From May 1, 2014, an additional staff was recruited for Veronika's one to one supervision during the week, for the weekend an additional auxiliary nurse was engaged. In the evening of May 3, 2014, an eighty-eight years old woman was referred to the closed ward of the clinic for suicidal tendencies. The staff placed her temporarily in the ward on the seat, which Veronika claimed for herself in order to watch her favourite broadcast "Sponge Bob". It seems that Veronika tore the old woman violently by the hair, tearing out bundles of hair and hitting her head on the floor. As a consequence, the old woman suffered a cerebral haemorrhage and died some three weeks later.

In June 2014, a neuropaediatrician examined Veronika. She described autistic patterns of behaviour. She suspected a genetic cause such as the Klinefelter-syndrome or fragile X-Chromosome. In the meantime, Veronika continued her aggressive behaviour and had to be isolated several times. On 27 November 2014, another serious incident occurred: Veronika tore out bundles of hair from a 55 year old woman who had upset her the day before.

On $1^{\text {st }}$ December 2014, Veronika was referred to a special clinic for the care of seriously impaired. Since then Veronika has been placed in a special ward for "challenging behaviour", where she gets a 1:1 care. According to the head nurse of the ward, there is literally nothing which has not been damaged by Veronika who caused expenses of up to 10,000.00 EUR. In the daytime, the mattresses had to be removed from her room since she would tear them to tatters. For the sake of the other inmates, Veronika had to be kept isolated. During the first months of her stay, her body weight could be lowered from $84.5 \mathrm{~kg}$ to $79.5 \mathrm{~kg}$.

\section{Forensic Psychiatric Assessment}

An institute for forensic psychology was mandated to establish a forensic-psychiatric assessment, but the experts failed to produce a diagnosis, hence this author was mandated with the task. During my examinations, which were performed in the presence of a staff member who advised me to watch my glasses, I faced a short, severely overweight young woman with a short haircut who was fully conscious and alert. During the conversation she would smile shyly avoiding eye contact. She was very distractible. Her speech was blurred. In her room, she kept a collection of soft dolphins. Altogether there was quite a good emotional rapport with me. As a privilege, I was allowed to play the "crocodile game" with her, where the loser symbolically loses one finger. 
Since the diagnostic procedures for the research of fragile X-Chromosome have been refined, a new assessment was ordered from the Institute of Medical Genetics of the University of Basle. The result was negative, the costs for the examination adding up to about 2,000.00 EUR. Hence, I abstained from ordering further examinations, even though, according to the laboratory, roughly 4000 possible gene loci were to be identified that could explain the present clinical picture.

\section{Diagnostic Considerations}

The former diagnosis of „minor mental retardation with significant impairment of behaviour requiring attention or treatment“ (ICD-10: F70.1) alone did not match with the amount of conduct disturbances displayed by Veronika. Since this pattern of behaviour could be followed since early childhood, the hypothesis of a periodically relapsing disorder as e.g. bipolar disorder, as it had been discussed in 2012 could clearly be rejected. Because of the persistence of her symptoms, which became even more difficult to manage when Veronika had reached somatic maturity, I also rejected the hypothesis of any schizophrenic like disorder such as e.g. Hebephrenia (ICD.10: F 20). The diagnosis "combined developmental disorder" that most of her former therapists had established, does not describe the pervasive nature of the disturbances of her social competence.

Actually, Veronika shows a "qualitative deviation in her mutual social interactions": Veronika is unable to adequately regulate her feelings of affection or rejection to others; for years, a 1:1 supervision had been required in order to protect herself and others. Her "infantile pattern of communication" corresponds to that of an infant. Eventually there is "a restricted, stereotyped, repetitive pattern of interests and activities" (catching small animals, destroying glasses, collecting soft animals). These qualitative abnormalities of conduct in all situations correspond to the so-called pervasive developmental disorder in the sense of infantile autism, formerly called "Kanner syndrome" (ICD-10: F 84.1). A number of "unspecified problems as phobias, sleep- and eating disorders, tantrums and (auto destructive) aggression" [4], which all could be observed in the case of Veronika, characterize pervasive developmental disorder. In a few cases, such symptoms go along with certain somatic syndromes, which are probably the cause of it: Cerebral palsy, hereditary rubella, tuberous sclerosis, cerebral lipoidosis, and the syndrome of fragile X-chromosome. In the case of Veronika, no such syndrome could be found to explain her psychiatric disorder.

Since it has so far not been possible to assign Veronika's psychiatric disorder to a deficiency of the genes, and no neuropsychiatric cause was identified, the diagnosis had to be established in a phenomenological way - as by the way is current practice for most psychiatric diagnoses;

- Infantile Autism (ICD-10: F84.0)

- minor mental retardation with significant impairment of behaviour requiring attention or treatment (ICD10: F70.1).

\section{Legal Capacity}

By assessing the moral capacities of Veronika, I found that they corresponded to level one of the 6-level scale of the American psychologist Kohlberg [5], which is the heteronomous level, where morals are defined as the avoidance of 
punishment. The heteronomous scale corresponds to the preconventional level of the development of morals, a state which normally should be overcome in favour of a higher level by the age of 9 .

The base of disturbed social interactions of people suffering from autism is according to latest theories a lack of "theory of mind" (ToM); i.e. a deficiency of the capacity to empathise, respectively understand or feel, what other people expect from one's social interactions. A lack of ToM does not necessarily mean an intellectual impairment. In the case of Veronika, she simply could not understand why the seriously ill old woman was unable to respect her habits. A lack of ToM does not equal lack of empathy; people such as e.g. a fraudster might suffer from a lack of empathy but certainly need a well-developed ToM in order to deceive their victims [6]. Whilst aggressive behaviour among boys is much more frequent than among girls, with children suffering from autism, the sex ratio of aggressive behaviour is 1:1. Stereotypic patterns of behaviour mean a risk of violent conduct: Autistic children who are disturbed in their stereotypic behaviour might be especially irritated [7].

In his forensic-psychiatric expertise, the author concluded that Veronika did not lack the capacity to understand her wrongdoing but was unable to act according to this insight. This means that her legal culpability was abrogated according to Art. 19.1 Swiss p.c.

\section{Judgement}

In August 2015, the youth court suspended the investigation for voluntary manslaughter due to the defendant's lack of legal culpability and, according to Art. 10 of the Swiss penal code for youth, placed her in an appropriate institution.

\section{Discussion}

In 1943, Kanner described 11 children who were unable to establish normal affective relationships. In contrast to schizophrenia where the sick person withdraws from society, these children never had had a relationship with their environment. Kanner transferred the notion of autism from adult to child psychiatry [8].

Nowadays, the term Kanner-syndrome has been replaced by autism-spectrum disorder [9]. About 10\% of autismspectrum disorders are showing a syndrome including somatic deformities, respectively dysmorphic signs can be identified [3]. Modern diagnostic procedures identify genetic variations which can be distinguished by frequency (common, rare, very rare), pattern of heredity (autosomal, X-chromosomal), kind of deficiency (structured incl. aneuploidy. "copy number variants", "indel", or "single-nucleotide variation") or its hereditary mechanism (additive, recessive, dominant or homozygote). Such deficiencies are neither specific - some of these variations are found in cases of schizophrenia - nor do they predict the severity of the disorder.

In the case of Veronika, further genetic investigations would have been interesting from a scientific point of view but without legal or therapeutic consequences. At present, an examination of the genes is only justifiable when suspected that a psychiatric disorder can be clearly ascribed to a genetic disorder [10]. As long as most psychiatric disorders cannot be clearly ascribed to a specific deficiency in the genome, psychiatric diagnoses remain mainly based on clinical findings. 


\section{References}

1. Fogden BC, Thomas SDM, Daffern M, et al. Crime and victimisation in people with intellectual disability: a case linkage study. BMC Psychiatry 16 (2016): 170.

2. Fitzpatrick SE, Svivorakiat L, Wink LK, et al. Aggression in autism spectrum disorder: presentation and treatment options. Neuropsychiatric Disease and Treatment 12 (2016): 1525-1538.

3. Persico AM, Napolioni V. Autism genetics. Behavioural Brain Research 251 (2013): 95-112.

4. Dilling H, WHO. Internationale Klassifikation psychischer Störungen: ICD-10 Kapitel V (F). Klinischdiagnostische Leitlinien (Edn 10) Bern: Hogrefe (2015).

5. Kohlberg L. Essays on Moral Development, Vol. I: The Philosophy of Moral Development. San Francisco, CA: Harper and Row (1981).

6. Krippl M, Karim M. "Theory of Mind" und ihre neuronalen Korrelate bei forensisch relevanten Störungen. Nervenarzt 8 (2011): 843-852.

7. Kanne MS, Mazurek MO. Aggression in Children and Adolescents with ASD: Prevalence and Risk Factors. Journal of Autism and Developmental Disorder 411 (2011): 926-937.

8. Kemper E, Domes G, Herpertz-Dahlmann B, et al. Autismus und autistische Störungen, Nervenarzt 81 (2010): 55-65.

9. Volkmar FR, McPartland JC. From Kanner to DSM-5: Autism as an evolving diagnostic concept. Annual Review of Clinical Psychology 10 (2014): 193-212.

10. De Rubeis S, Buxbaum JD. Genetics and genomics of autism spectrum disorder: embracing complexity. Human Molecular Genetics 24 (2015): R24-R31.

Citation: Andreas Frei. Autism Spectrum Disorder Combined with Mental Retardation-An Indication for Molecular-Genetic Examination?. Journal of Psychiatry and Psychiatric Disorders 2 (2018): 65-70.

\footnotetext{
(c)

This article is an open access article distributed under the terms and conditions of the Creative Commons Attribution (CC-BY) license 4.0
} 